\title{
ASSISTÊNCIA ESTUDANTIL E AÇÕES AFIRMATIVAS: UM ESTUDO DAS CONDIÇÕES MATERIAIS E SIMBÓLICAS
}

\author{
Natalino Neves da Silva ${ }^{1}$ \\ Adilson Pereira dos Santos ${ }^{2}$ \\ Jane Maria dos Santos Reis ${ }^{3}$
}

\begin{abstract}
RESUMO: Este artigo buscou compreender a política de assistência estudantil adotada por três universidades federais mineiras. Nesta investigação, pretendeu-se responder: quais são as condições materiais e simbólicas que favorecem a permanência de estudantes ingressantes por meio das Políticas de Ações Afirmativas (PAA)? O estudo é de caráter qualitativo e a metodologia adotada contou com levantamento bibliográfico, análise documental e aplicação de questionário aos(às) gestores(as) dessas universidades. Os resultados apontam que o processo de democratização do Ensino Superior está intrinsecamente relacionado ao acesso e à garantia das condições materiais e simbólicas capazes de assegurar a permanência desse novo sujeito, negro e negra, ingressante, por meio das PAA no Ensino Superior.
\end{abstract}

Palavras-chave: Políticas de Ações Afirmativas. Permanência. Cotas raciais. Ensino Superior.

STUDENT ASSISTANCE AND AFFIRMATIVE ACTIONS: A STUDY ON MATERIAL AND SYMBOLIC CONDITIONS

\begin{abstract}
This article is the result of a research that sought to understand the student assistance policy adopted by three federal universities in Minas Gerais, Brazil. Therefore, we question: what are the material and symbolic conditions that favor the permanence of freshmen students through Affirmative Action Policies (from the Portuguese, Políticas de Ações Afirmativas; PAA)? The study is qualitative in nature and the methodology adopted included a bibliographic survey, document analysis and a questionnaire applied to managers. The results show that the process of democratization in higher education is intrinsically related to access, but also to the guarantee of material and symbolic conditions capable of ensuring the permanence of this new black subject entering higher education through PAA.

Keywords: Affirmative Action Policies. Permanence. Racial quotas. Higher education.

1.Universidade Federal de Minas Gerais - Departamento de Administração Escolar - Faculdade de Educação - Belo Horizonte

2.Universidade Federal de Ouro Preto - Pró-reitoria de Graduação - Ouro Preto (MG), Brasil. E-mail: adilson.santos@ufop.edu.br

3.Universidade Federal de Uberlândia - Diretoria de Ensino - Uberlândia (MG), Brasil. E-mail: jane05@uol.com.br

Editores convidados: Nilma Lino Gomes, José Eustáquio Brito e Paulo Vinicius Baptista da Silva
\end{abstract} (MG), Brasil. E-mail: natalinosilva@ufmg.br

Editor de Seção: Salomão Barros Ximenes 


\section{ASISTENCIA AL ESTUDIANTE Y ACCIONES AFIRMATIVAS: ESTUDIO DE LAS CONDICIONES MATERIALES Y SIMBÓLICAS}

RESUMEN: Este artículo es el resultado de una investigación que buscó comprender la política de asistencia al estudiante adoptada por tres universidades federales en Minas Gerais, Brasil. Por tanto, ¿ cuáles son las condiciones materiales y simbólicas que favorecen la permanencia de los estudiantes de primer año a través de Políticas de Acción Afirmativa (PAA)? El estudio es de naturaleza cualitativa y la metodología adoptada incluyó encuesta bibliográfica, análisis de documentos y aplicación de un cuestionario a los administradores. Los resultados muestran que el proceso de democratización en la educación superior está intrínsecamente relacionado con el acceso, pero también con la garantía de condiciones materiales y simbólicas capaces de asegurar la permanencia de este nuevo sujeto, negro y negra, que ingresa a la educación superior a través de las PAA.

Palabras-clave: Políticas de Acción Afirmativa. Permanencia. Cuotas raciales. Enseñanza superior.

A Lei n. 12.711/12 é parte integrante do processo de implementação das Políticas de Ações Afirmativas (PAA), cujo objetivo é assegurar o ingresso nos ensinos Superior e Técnico de nível médio em instituições federais a segmentos sociais com histórico de desigualdades e exclusão. Essas políticas compõem um conjunto mais amplo de ações, na perspectiva de democratização da educação com inclusão social, reivindicadas pelas metas 8 e 12 do Plano Nacional de Educação (PNE), aprovado pela Lei n. 13.005/2014 (BRASIL, 2014).

As reinvindicações por um sistema de Ensino Superior e Técnico democrático e includente são pleiteadas no Brasil desde longa data. Isso porque o caráter elitista dessas modalidades de ensino remonta à sua origem ${ }^{1}$ e se arrasta até o século XXI. De acordo com Martin Trow (1973), um sistema elitista é aquele cuja cobertura alcança até $15 \%$ do grupo etário de 18 a 24 anos, percentual atingido pelo Brasil no fim da primeira década deste século (GOMES; MORAES, 2012).

O debate em torno das PAA no país se intensificou após a III Conferência Mundial Contra o Racismo, Discriminação Racial, Xenofobia e Intolerâncias Correlatas, realizada em Durban no ano de 2001. Nesse sentido, a discussão acerca da democratização do Ensino Superior constituiu nova agenda de luta de setores progressistas sociais, bandeira outrora empunhada pela União Nacional dos Estudantes (UNE) nos anos de 1960.

A democratização historicamente reclamada não se limitava à garantia do acesso, visto que ela necessitaria se concretizar acompanhada de condições materiais e simbólicas que assegurassem a permanência, a promoção de uma educação antirracista e o êxito do público estudantil ingressante por meio dessas políticas. Nessa perspectiva, a pesquisadora Aparecida Joly Gouveia, em meados do século XX, defendia que, "além de abrir as portas da universidade, era necessário dotar tais grupos de recursos que assegurassem a sua permanência e o seu êxito acadêmico" (GOUVEIA, 1968, p. 35).

Passados mais de vinte anos de experiências de PAA no Ensino Superior e, em particular, quase uma década da sua implementação na totalidade das instituições federais, por força da Lei n. 12.711/12, conhecida popularmente como Lei de Cotas, tal modalidade de acesso tem sido universalizada nas instituições de ensino.

O Censo da Educação Superior, com as inúmeras produções acadêmicas, bem como a Pesquisa Nacional do Perfil dos(as) Graduandos(as) realizada pela Associação Nacional dos Dirigentes das Instituições 
Federais de Ensino Superior (Andifes) em 2018 comprovam haver uma reconfiguração do perfil estudantil universitário após a adoção das PAA pelas universidades federais. Esse fator, em parte, pode ser tributado à Lei n. 12.711, associada a outras iniciativas de democratização com inclusão social.

Indaga-se, portanto, quais são as condições materiais e simbólicas que favorecem a permanência e, consequentemente, o êxito acadêmico de estudantes ingressantes por meio dessas políticas. De modo mais específico, interessa-nos saber quais são as dificuldades orçamentárias enfrentadas pelas instituições do ponto de vista da assistência estudantil. Para além disso, as universidades desenvolvem algum tipo de programa voltado para trabalhar especificamente com esse público?

Nessa perspectiva, realizamos um estudo que buscou compreender a política de assistência estudantil adotada por três universidades federais do Estado de Minas Gerais, quais sejam: Universidade Federal de Minas Gerais (UFMG), Universidade Federal de Ouro Preto (UFOP) e Universidade Federal de Uberlândia (UFU $)^{2}$ no que concerne à garantia de suportes materiais e simbólicos destinados aos(às) estudantes ingressantes pelas cotas raciais. Ademais, a investigação teve ainda como intenção: 1) conhecer o perfil socioeconômico e cultural dos ingressantes a partir do advento da Lei 12.711/2012; 2) analisar a destinação orçamentária prevista no Plano Nacional de Assistência Estudantil (PNAES); 3) identificar as políticas institucionais de permanência material e simbólica, com foco nos ingressos por meio das cotas raciais; e 4) refletir sobre o compromisso institucional em relação às políticas de promoção da igualdade étnico-racial.

Dada a natureza do problema de pesquisa, o estudo é de caráter qualitativo (FLICK, 2004). A realização do estado de conhecimento a respeito do tema em questão se apresentou como abordagem metodológica privilegiada, uma vez que nos possibilita o "desafio de conhecer o já construído e produzido para depois buscar o que ainda não foi feito” (FERREIRA, 2002, p. 259).

Assim, foram consultadas as seguintes plataformas: Banco Digital de Teses e Dissertações do Instituto Brasileiro em Informação em Ciência e Tecnologia (IBICT); Biblioteca Eletrônica Scientific Eletronic Library (SciELO); Portal de Periódicos da Coordenação de Aperfeiçoamento de Pessoal de Nível Superior (CAPES); Google Scholar, entre outros, no sentido de averiguar como essa temática tem emergido na produção de conhecimento.

A esse respeito, apesar do expressivo aumento de produções acadêmicas realizadas nos últimos anos voltadas para compreender os impactos e o acompanhamento dos modos de implementação da Lei n. 12.711 nas Instituições de Ensino Superior (IES), percebe-se que os trabalhos destinados a analisar, de modo específico, a política estudantil, bem como os suportes materiais e simbólicos resultantes dela, encontram-se ainda bastante incipientes na área (ARTES; MENA-CHALCO, 2017; BARRETO et al, 2020; DAFLON; FÉRES JUNIOR; CAMPOS, 2013; SANTOS, 2009; SILVÉRIO, 2018; entre outros).

A análise documental se apresentou também como uma "[...] técnica valiosa de abordagem de dados qualitativos, seja complementando as informações obtidas por outras técnicas, seja desvelando aspectos novos de um tema ou problema" (ANDRÉ; LÜDKE, 1986, p. 38). Com isso, foram consultados os documentos institucionais que normatizam as Políticas de Assistência Estudantil de cada uma das instituições, bem como as iniciativas acadêmicas direcionadas aos(às) estudantes de graduação.

Os seguintes documentos fizeram parte do corpus de análise: 1) Lei Orçamentária Anual e os aportes de recursos na rubrica 4002 (assistência estudantil); 2) políticas institucionais de aplicação de tais recursos; 3 ) eventuais iniciativas suplementares (como a criação de Pró-reitoria para atuar no processo de implementação dessas políticas, a constituição de projetos e programas); entre outros.

Foram aplicados ainda questionários estruturados com questões abertas direcionadas aos(às) três gestores(as) das respectivas instituições, que atuam como responsáveis por implementar a política estudantil. 
A utilização desse instrumento tinha a intenção de elucidar e aprofundar as indagações levantadas pelo estudo.

O processo de análise dos dados levantados se estrutura nas seguintes etapas:

1. Levantamento e leitura;

2. Organização do material coletado em planilha Microsoft Excel;

3. Sistematização e organização a partir das contribuições da análise de conteúdo de Laurence Bardin (2006); e, por fim,

4. Definição de categorias de análises.

O artigo está organizado, além desta introdução e das considerações finais, em quatro subtópicos:

1. Democratização do acesso à educação superior e ações afirmativas, que situa as PAA no Ensino Superior;

2. Situando o contexto da pesquisa, em que é realizada uma análise comparativa entre três universidades federais mineiras investigadas;

3. Políticas de Assistência Estudantil: suportes materiais e simbólicos necessários à verdadeira democratização, que defende a noção de permanência a partir de duas perspectivas interrelacionadas: material e simbólica; e

4. Programas de Assistência Estudantil nas universidades pesquisadas, elucidando o levantamento e a análise de dados relacionados aos Programas de Assistência Estudantil.

\section{Democratização do Acesso à Educação Superior e as Ações Afirmativas}

As PAA constituem, neste século XXI, importante marco histórico a favor da promoção da equidade socioeconômica, étnico-racial e de gênero ${ }^{3} \mathrm{~A}$ adoção dessas políticas repercute em diferentes áreas do conhecimento, a saber: sociais, humanas e da saúde, jurídico-econômica, educacional, político-cultural, entre outras. Sua origem está relacionada a diversas situações de desigualdades sociorraciais, econômicas e de gênero verificadas, sobretudo, em contextos sociais que vivenciaram experiências coloniais e de exploração do escravismo negro (MOEHLECKE, 2002).

Assim sendo, as ações afirmativas, no entendimento do jurista Joaquim Barbosa Gomes (2001), são um conjunto de políticas públicas e privadas de caráter compulsório, facultativo ou voluntário, concebidas, com vistas ao combate à discriminação racial, de gênero e de origem nacional, bem como à correção dos efeitos presentes da discriminação praticada no passado. Essas ações têm por objetivo a concretização do ideal de efetiva igualdade de acesso a bens fundamentais, como a educação e o emprego.

Originariamente, as ações afirmativas foram reivindicadas pelo movimento social negro para a população negra. ${ }^{4}$ Entretanto, por meio do consenso político, que resultou na Lei n. 12.711, outros segmentos sociais foram incorporados como beneficiários. De tal sorte, a lei supracitada foi imposta às universidades federais e à Rede Federal de Educação Profissional, Científica e Tecnológica, ${ }^{5}$ visando promover maior equidade em relação ao público estudantil, no que se refere à procedência escolar, renda, pertencimento étnico-racial e deficiência.

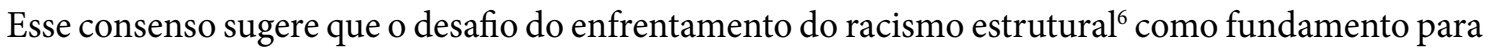
reparação foi evitado nessa norma. Logo, indaga-se: a sua conquista foi seguida de uma consciência maior da luta e da resistência do sujeito político negro por parte da sociedade brasileira? Isso porque as políticas públicas, alinhadas ao processo de implementação das PAA, devem buscar reparar as assimetrias sociorraciais e educacionais produzidas historicamente pelo racismo estrutural e estruturante nessa sociedade. Além disso, 
devem promover uma verdadeira reeducação para as relações étnico-raciais, uma vez que as ações afirmativas são portadoras de dois significados concomitantes, quais sejam: "não só como movimento de luta política pela correção das desigualdades raciais, mas também como lócus em que confluem princípios gerais de um outro modelo de racionalidade e saberes emancipatórios produzidos pelo Movimento Negro ao longo dos tempos" (GOMES, 2011, p. 148).

Garantir o direito à educação superior e técnica de nível médio para os novos sujeitos ingressantes por meio das PAA implica, entre outras coisas, possibilitar o ambiente educacional mais diverso, plural e antirracista. Nesse sentido, várias IES deram início ao processo de implementação das cotas raciais a partir do ano de 2013, a fim de cumprir o dispositivo normativo legal previsto na Lei n. 12.711/12. Segundo essa norma, 50\% dessas cotas devem ser oferecidas em cada curso/turno nas instituições federais de Ensino Superior e Técnico de nível médio e destinadas a candidatos egressos de escolas públicas, pessoas de baixa renda, pretos, pardos indígenas e pessoas com deficiências. Esse último grupo foi incorporado às reservas pela Lei n. 13.409/2016.

Do ponto de vista operacional, as vagas reservadas pela Lei de Cotas, em primeiro lugar, são destinadas a candidatos egressos de escolas públicas. Em seguida, são subdivididas em cotas específicas: metade para estudantes com renda familiar bruta igual ou inferior a um salário mínimo e meio per capita. Nos dois grupos de baixa renda ou independentemente da renda, deve haver as reservas para o critério étnico-racial (pretos e pardos) e por deficiências, em conformidade com os artigos $3^{\circ}$ e $5^{\circ}$ da lei citada. $\mathrm{O}$ percentual da reserva “deverá se basear na proporção que estes grupos representam na população da unidade da Federação onde está instalada a instituição, segundo o último censo do Instituto Brasileiro de Geografia e Estatística" (BRASIL, 2012, s. p.).

A despeito da secundarização do critério racial na Lei de Cotas, a obrigatoriedade de sua adoção em toda Rede Federal vinculada ao MEC inaugurou um momento inédito até então na história das instituições federais brasileiras, ao promover o acesso da população negra nesses níveis de ensino.

Para melhor compreensão da Lei n. 12.711, torna-se oportuno recuperar, ainda que de forma breve, a inserção das reivindicações por PAA no contexto das lutas pela democratização do acesso ao Ensino Superior, marcadamente elitista. A destinação de vagas para determinados grupos com histórico de desigualdades reafirma, nos debates sobre a democratização, o ingrediente da inclusão social. Isso porque as expansões da educação superior recentes não asseguram condições de acesso a tais grupos. A ampliação do número de vagas, mantendo o tradicional vestibular como estratégia exclusiva de acesso, revela-se um importante obstáculo nesse sentido.

Nesse ínterim, cabe lembrar que, entre os anos de 2001 e 2012, diversas IES adotaram algum tipo de iniciativa por pressões sociais, realizadas pelo movimento negro e pela sociedade civil organizada, relacionadas à democratização do acesso ao Ensino Superior, de forma compulsória ou voluntária (CARVALHO, 2016). Nesse período, as primeiras iniciativas de ações afirmativas, na modalidade de acesso à educação superior, ocorreram entre os anos de 2002 e 2004, nas Universidades do Estado do Rio de Janeiro (Uerj), do Norte Fluminense (UENF), do Estado do Mato Grosso do Sul (UEMS), do Estado da Bahia (Uneb) e de Brasília (UnB).

As três primeiras universidades citadas o fizeram por força de leis estaduais; e as outras duas, à luz de decisão autônoma das próprias IES. A adoção do critério racial advindo dessas iniciativas foi alvo de muitas críticas e polarizações. A polêmica ganhou espaço no interior das instituições, na mídia, no judiciário etc., e só foi dirimida com o julgamento de sua constitucionalidade por parte do Superior Tribunal Federal (STF), ${ }^{7}$ meses antes da aprovação da Lei n. 12.711.

Segundo Santos (2020), das 59 universidades federais existentes em 2011, quarenta adotavam algum tipo de ação afirmativa, com desenhos e públicos beneficiários variados. Esse foi, pois, o contexto que 
enredou a aprovação da Lei n. 12.711, a qual teve o mérito de universalizar, na rede federal, as PAA, que já estavam presentes na maioria das universidades.

A esse respeito, tal reconfiguração vem ocorrendo antes mesmo dos efeitos dessa política. Ao cruzarmos os dados referentes a sexo e cor/raça, é possível verificar a ampliação do acesso por parte da população universitária negra no período compreendido entre 1988 e 2008 . Observa-se que, apesar das assimetrias existentes entre negros e não negros, o grupo de mulheres negras é notadamente maior: 4,1\% (1988) e 20\% (2008). Isso demonstra o resultado positivo de implantação de processos relacionados à democratização do Ensino Superior, conforme descrito na Tabela 1.

Tabela 1. Taxa de matrículas no Ensino Superior por sexo e cor/raça (\%)

\begin{tabular}{cccc}
\hline & $\mathbf{1 9 8 8}$ & $\mathbf{2 0 0 8}$ & 39,9 \\
\hline Mulheres brancas & 12,4 & 20 & \\
\hline Mulheres negras & 4,1 & 31,7 & 13 \\
\hline Homens brancos & 12,3 & 3,1 & 13 \\
\hline Homens negros
\end{tabular}

Fonte: Paixão (2010, p. 227).

Mais recentemente, a publicação da V Pesquisa Nacional do Perfil Socioeconômico e Cultural dos(as) Graduandos(as) das Universidades Federais, em 2018, realizada pela Andifes por meio do Fórum Nacional de Pró-reitores de Assuntos Estudantis (FONAPRACE) corrobora esses resultados e endossa que as mudanças na composição de cor e raça dos estudantes das Instituições Federais de Ensino Superior (IFES) foram bastante significativas nos últimos quinze anos.

Os cursos ofertados pelas IFES contam hoje com maior representatividade de gênero, cor/raça e classe social. A alteração desse perfil é atribuída, "em parte, ao resultado da adoção de políticas de ação afirmativa nas universidades federais. De 2003 a 2018, os pardos aumentaram sua participação entre estudantes em 11 pontos percentuais e os pretos mais que dobraram" (ANDIFES, 2019, p. 33).

Tabela 2. Graduandos(as) e população brasileira segundo cor/raça - 1996 a 2018 (\%)

\begin{tabular}{cccccccc}
\hline Cor ou raça & Pesquisa & $\mathbf{1 9 9 6}$ & $\mathbf{2 0 0 3}$ & $\mathbf{2 0 1 0}$ & $\mathbf{2 0 1 4}$ & $\mathbf{2 0 1 8}$ \\
\hline \multirow{2}{*}{ Amarela } & IFES & - & 4,5 & 3,1 & 2,3 & 2,1 \\
\cline { 2 - 7 } & PNAD/IBGE & 0,4 & 0,4 & 1,1 & 0,5 & 0,4 \\
\hline \multirow{2}{*}{ Branca } & IFES & - & 59,4 & 53,9 & 45,7 & 43,3 \\
\cline { 2 - 7 } & PNAD/IBGE & 55,2 & 52,0 & 47,7 & 45,5 & 38,6 \\
\hline \multirow{2}{*}{ Parda } & IFES & - & 28,3 & 32,1 & 37,8 & 39,2 \\
\cline { 2 - 8 } & PNAD/IBGE & 38,2 & 41,5 & 43,1 & 45,1 & 52,5 \\
\hline \multirow{2}{*}{ Preta } & IFES & - & 5,9 & 8,7 & 9,8 & 12,0 \\
\cline { 2 - 7 } & PNAD/IBGE & 6,0 & 5,9 & 7,6 & 0,6 & 8,1 \\
\hline \multirow{2}{*}{ Indígena } & IFES & - & 2,0 & 0,9 & 0,6 & 0,9 \\
\cline { 2 - 7 } & PNAD/IBGE & 0,2 & 0,2 & 0,4 & 0,4 & 0,4 \\
\hline \multirow{2}{*}{ Sem declaração } & IFES & - & - & - & 3,8 & 2,5 \\
\cline { 2 - 7 } & PNAD/IBGE & - & - & - & \\
\hline
\end{tabular}

Fontes: Andifes (2019).

Esses dados indicam que as PAA vêm contribuindo para inserir novos sujeitos, negros e negras, nas IES brasileiras. Essa contribuição relaciona-se, sobretudo, a esse acesso. No entanto, a verdadeira 
democratização deve ainda ser refletida pela garantia das condições de permanência, visando ao êxito da trajetória estudantil dos ingressantes dessas políticas. É sobre isso que pretendemos discutir a seguir.

\section{Situando o Contexto de Pesquisa}

As universidades federais UFMG e UFOP estão localizadas na mesorregião metropolitana de Belo Horizonte e a UFU pertence à mesorregião do Triângulo Mineiro e Alto Paranaíba. A UFMG, de acordo com a avaliação realizada pelo Instituto Nacional de Estudos e Pesquisas Educacionais Anísio Teixeira (Inep), é considerada uma das melhores universidades do país.

Os resultados divulgados pelo Exame Nacional de Desempenho de Estudantes (Enade) no triênio 2017-2018-2019 revelam que, dos 71 cursos de graduação avaliados nessa universidade, 41 (58\%) têm conceito máximo (nota 5) e 21 (29\%) têm conceito 4,7 (10\%). Quase 90\% dos cursos de graduação possuem conceito 4 ou 5 no Enade, o que representa o resultado de excelência no exame (INEP, 2019).

Até o ano de 2007, não havia nenhum tipo de Política de Ação Afirmativa desenvolvida por parte da instituição. ${ }^{8}$ A UFMG inicia as discussões a respeito da inclusão social visando à adesão ao Programa de Apoio a Planos de Reestruturação e Expansão das Universidades Federais (Reuni), instituído pelo então presidente Luiz Inácio Lula da Silva por meio do Decreto n. 6 096/07, que incidiu sobre a ampliação das vagas e sobre a maior oferta de cursos noturnos nas universidades federais.

No final de 2006, a IES organiza o seminário intitulado Universidade Pública e Inclusão Social Experiências e Imaginação, que tinha o propósito de discutir a criação de mecanismos institucionais voltados para a democratização da universidade pública (PEIXOTO; ARANHA, 2008). À época, apenas 28\%, isto é, dezesseis universidades federais haviam implementado algum tipo de reserva de vagas para ingresso nos cursos de graduação, número que se ampliou até 2012, conforme já retratado.

Sendo uma das últimas universidades a adotar as ações afirmativas, pressionada pela Comissão de Estudo e Acompanhamento de Medidas de Inclusão Social (CAIS), designada pelo Conselho Universitário para propor políticas para o público estudantil, a instituição passou a adotar a Política de Bônus ${ }^{9}$ a partir de 2009, que vigorou até o ano de 2012, com a aprovação da Lei n. 12.711 (GONZAGA, 2017).

A implementação das cotas raciais e para candidatos de baixa renda ocorreu em 2013, por força da Lei supracitada. A instituição, posteriormente, em 2014, aderiu ao Sistema de Seleção Unificada (SiSU). O ingresso com, no mínimo, 50\% das vagas de estudantes com o perfil dessas políticas aconteceu no ano de 2016. Nesse cenário, foi criada a Pró-reitoria de Assuntos Estudantis (PRAE), em novembro de 2014. ${ }^{10}$ Sua atuação abrange três dimensões interconectadas, quais sejam: 1) ações afirmativas; 2) assistência estudantil; e 3) apoio a projetos de estudantes.

Com a adesão às PAA, notou-se que quase a metade dos(as) estudantes $(49,3 \%)$ que chegaram aos cursos de graduação da instituição no primeiro período letivo de 2018 eram negros(as). Por conseguinte, houve uma demanda pelo fortalecimento da Política de Assistência Estudantil, tendo em vista que custos com essa assistência passaram de $\mathrm{R} \$ 22,5$ milhões, em 2013, para $\mathrm{R} \$ 37,3$ milhões, em 2017, período em que a UFMG buscou democratizar o Ensino Superior por meio das políticas afirmativas.

Conforme Relatórios Enade (2017, 2018 e 2019), a UFOP conta com 55 cursos de graduação, dos quais 53 participaram do Enade entre os anos de 2017 e 2019. A maioria dos cursos obteve conceitos 5 (30,2\%) e $4(43,4 \%)$; dez cursos $(18,9 \%)$ receberam conceito $3(18,9 \%)$; e quatro cursos receberam conceito $2(7,5 \%)$,

No ano de 2004, a IES foi provocada pelo movimento negro a adotar cotas raciais nos seus cursos. Passaram-se quatro anos de acirrados debates, quando, em 2008, a instituição aprovou uma política própria 
de ação afirmativa, sendo a segunda universidade mineira a fazê-lo. Essa política reservava $30 \%$ de vagas para candidatos que tivessem cursado integralmente e concluído o ensino médio em escolas públicas. Durante sua vigência, além de aumentar a presença de egressos de escolas públicas, essa medida contribuiu para a ampliação de negros(as) e pessoas de baixa renda no corpo discente.

No ano de 2007, paralelamente às discussões para avaliar a adesão ao Reuni, a UFOP criou sua Próreitoria Especial de Assuntos Comunitários e Estudantis (PRACE), cujo objetivo é proporcionar condições de acesso e permanência aos estudantes, técnicos administrativos e docentes da instituição, garantindo, assim, o bem-estar psicossocial de toda a comunidade universitária.

Para o recrutamento de estudantes, a IES utilizava as notas do Enem para composição do desempenho dos candidatos no vestibular desde 1999. Em 2011, extinguiu o exame vestibular e aderiu ao SiSU. No ano de 2013, com a aprovação da Lei n. 12.711, a instituição adaptou sua Política de Ação Afirmativa, incorporando os critérios de renda e étnico-racial aos processos seletivos. Mais tarde, em 2017, incorporou as pessoas com deficiência, seguindo a orientação da Lei n. 13.409/2016. No primeiro ano de vigência da Lei de Cotas, a UFOP empenhou R \$ 7,3 milhões de recursos para a assistência estudantil, valor que chegou a R\$ 9,5 milhões em 2017.

A UFU possui 78 cursos de graduação, sendo que, do total de 24 cursos avaliados no Enade 2019, três obtiveram conceito máximo (nota 5). São eles: Engenharia Civil, Engenharia Florestal e Nutrição. Quatorze tiveram nota 4 e sete cursos alcançaram nota 3 . No que se refere às cotas raciais, há indícios, desde 2003, de pressões por parte do movimento negro e, posteriormente, do Núcleo de Estudos Afro-brasileiros (NEAB), em 2006. Entretanto, somente após a institucionalização da Lei de Cotas, essa IES adotou compulsoriamente esse dispositivo legal, com a implantação de uma política de ação afirmativa voltada para a reserva de vagas destinadas aos candidatos negros e indígenas.

A UFU aderiu ao SiSU, no ano de 2012, para as entradas anuais e permanece com vestibular na entrada do meio do ano, tendo, dessa forma, dois processos seletivos por ano. Na Fig. 1, apresentam-se os dados atualizados, sistematizados pela Pró-reitoria de Assuntos Estudantis da UFU, acerca do atual cenário de ingressantes cotistas (todas as modalidades) na graduação:

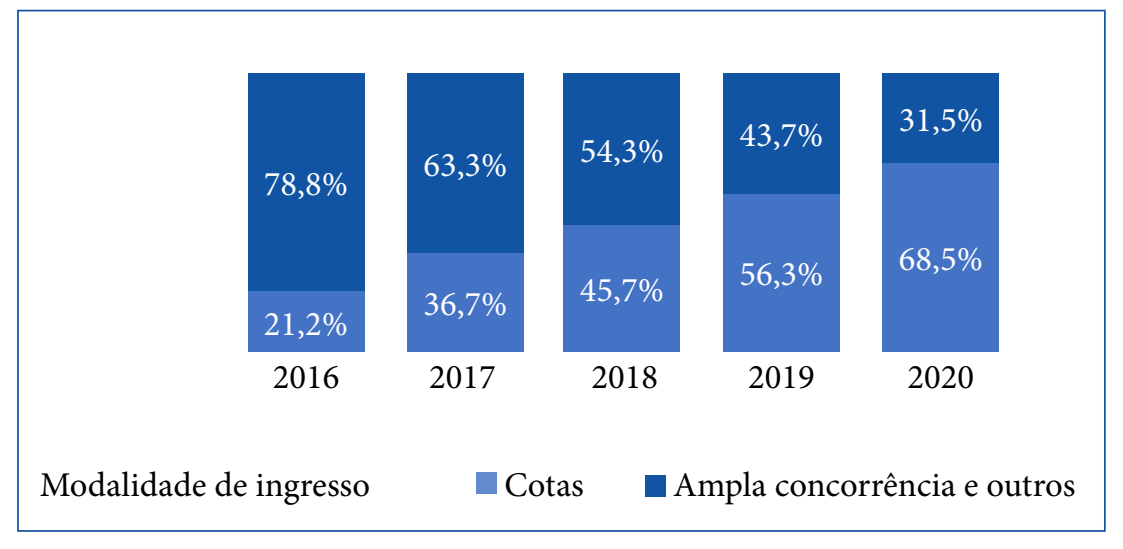

Fonte: PROAE UFU.

Figura 1. Porcentagem de modalidade de ingressantes cotistas e ampla concorrência

Atualmente, a UFU possui sistema de reserva de cotas raciais em todas as suas modalidades de ingresso: 1) educação básica (Colégio de Aplicação - pioneiro no contexto nacional de implementação de cotas na educação infantil e Ensino Fundamental); 2) educação profissional e tecnológica; 3) graduação (com a maior experiência); 4) pós-graduação (mestrados e doutorados - sendo a modalidade de ensino mais recente 
no que tange à implementação da comissão de heteroidentificação); e 5) concursos públicos (docentes e técnicos-administrativos em educação). Os aportes de recursos para a UFU por meio do PNAES no ano inicial de implantação da Lei de Cotas foram de R\$ 13 milhões, em 2013, e R\$ 22 milhões, em 2017.

No intervalo de quinze anos, compreendido entre 2005 e 2019, as três IES investigadas expandiram significativamente. $\mathrm{O}$ reflexo disso é que essas instituições ampliaram os números de cursos de graduação oferecidos. A UFU registrou crescimento de 67,0\%, a UFOP ampliou em 49,5\% e a UFMG, 47,3\%.

No que se refere às matrículas na graduação, a expansão na UFOP foi de 60,4\%; na UFU, de 47,0\%; e na UFMG, de 31,7\%. Seguindo a mesma tendência, o corpo docente registrou a elevação de $62,8 \%$ na UFOP; 47,1\% na UFU; e 31,3\% na UFMG, cujos valores em números absolutos são apresentados na Tabela 3.

Tabela 3. Evolução do número de cursos, matrículas e docentes

\begin{tabular}{ccccccccccc}
\hline \multirow{2}{*}{ IES } & \multicolumn{3}{c}{ Cursos } & \multicolumn{3}{c}{ Matrículas } & \multicolumn{3}{c}{ Docentes } \\
\cline { 2 - 12 } & $\mathbf{2 0 0 5}$ & $\mathbf{2 0 1 2}$ & $\mathbf{2 0 1 9}$ & $\mathbf{2 0 0 5}$ & $\mathbf{2 0 1 2}$ & $\mathbf{2 0 1 9}$ & $\mathbf{2 0 0 5}$ & $\mathbf{2 0 1 2}$ & $\mathbf{2 0 1 9}$ \\
\hline UFMG & 48 & 148 & 95 & 21455 & 32638 & 31.414 & 2405 & 3021 & 3.500 \\
\hline UFOP & 29 & 50 & 55 & 4821 & 13846 & 12.185 & 295 & 853 & 794 \\
\hline UFU & 32 & 124 & 97 & 11.918 & 20672 & 22.472 & 1.049 & 1742 & 1984 \\
\hline
\end{tabular}

Fonte: Sinopse Estatística do Ensino Superior (2005; 2012; 2019).

Nos termos do art. $8^{\circ}$ da Lei n. 12.711, as instituições deveriam implementar, no mínimo, 25\% da reserva de vagas prevista a cada ano, num prazo máximo de quatro anos. No caso da UFU, foi aplicada, desde o primeiro ano, a totalidade da reserva; já a UFOP reservou 30,0\% em 2013; e a UFMG, 12,5\%, como podemos observar na Tabela 4.

Tabela 4. Percentual de reserva de vagas entre 2013-2016

\begin{tabular}{ccccc}
\hline Universidade & $\mathbf{2 0 1 3}$ & $\mathbf{2 0 1 4}$ & $\mathbf{2 0 1 5}$ & $\mathbf{2 0 1 6}$ \\
\hline Exigência da Lei & 12,5 & 25,0 & 37,5 & 50,0 \\
\hline UFMG & 12,5 & 25,0 & 37,5 & 50,0 \\
\hline UFOP & 30,0 & 30,0 & 37,5 & 50,0 \\
\hline UFU & 50,0 & 50,0 & 50,0 & 50,0 \\
\hline
\end{tabular}

Fonte: Elaboração própria com base nos editais de seleção das IES.

Considerando que os segmentos de beneficiários das reservas de vagas são de baixa renda, as três IES passaram a receber pessoas com demandas materiais de permanência. Tendo em vista que compete à União assegurar os recursos financeiros por ocasião do aumento dessa demanda, o que tem se verificado, nos últimos anos, é a imposição de restrições orçamentárias por parte do Governo Federal, comprometendo, com isso, a efetivação democrática em relação à implementação das PAA (FREITAS; CORNÉLIO, 2021).

\section{Políticas de Assistência Estudantil: Suportes Materiais e Simbólicos Necessários à Verdadeira Democratização}

Conforme visto, a Lei n. 12.711/12, bem como outras iniciativas desenvolvidas no âmbito institucional, estão promovendo o acesso à educação superior e técnica de nível médio no que tange à inclusão 
social. Não obstante, no que concerne ao processo de democratização, faz-se necessário também notar se as condições materiais e simbólicas ofertadas são capazes de assegurar a permanência do público juvenil, negro e negra, visando ao êxito acadêmico. A noção de permanência tratada aqui vislumbra, portanto, essas duas perspectivas: material e simbólica.

Segundo Santos (2009), o desafio da permanência material consiste em assegurar ao(à) estudante a garantia de recursos, como equipamentos, material didático, operacionais, entre outros. A ausência desses recursos pode levar o(a) estudante a não ter condições de acompanhar ou vivenciar plenamente as atividades acadêmicas no interior da universidade. A ideia de permanência simbólica, por sua vez, está diretamente relacionada ao fato de que tais estudantes que adentraram a universidade originam-se das classes populares geralmente de forma pioneira. Em outros termos, na maioria das vezes, são os primeiros de suas famílias a ingressarem no Ensino Superior. Nesse contexto, os primeiros contatos com essas instituições costumam ser de estranhamento, devido ao fato de elas apresentarem um universo muito distante do seu.

Esses jovens são como Outsider, ou seja, não são membros de uma "boa sociedade" estão fora dela. Já os "outros" são estabelecidos, possuem uma identidade social construída a partir de uma combinação singular de tradição, autoridade e influência (SANTOS, 2009, p. 74).

A estratégia oficial adotada por pelas IES visando à garantia da permanência encontra-se no Programa Nacional de Assistência Estudantil (PNAES) ${ }^{11}$ do MEC, cuja finalidade consiste em ampliar as condições materiais necessárias à continuidade do público estudantil nas universidades. Os objetivos do PNAES são: 1) democratizar as condições de permanência dos jovens no Ensino Superior; 2) minimizar os efeitos das desigualdades sociais e regionais na permanência e na conclusão da educação superior; 3 ) reduzir as taxas de retenção e evasão; e 4) contribuir para a promoção da inclusão social pela educação.

Por conseguinte, as ações de assistência estudantil devem focar em: 1) moradia estudantil; 2) alimentação; 3) transporte; 4) atenção à saúde; 5) inclusão digital; 6) cultura; 7) esporte; 8) creche; 9) apoio pedagógico; e 10) acesso, participação e aprendizagem de estudantes com deficiência, transtornos globais do desenvolvimento e altas habilidades e superdotação (BRASIL, 2010a).

O Poder Legislativo aprova, na Lei Orçamentária Anual (LOA), os valores a serem destinados a cada uma das IES para aplicação no PNAES. No período que sucedeu a institucionalização das reservas de vagas estabelecidas pela Lei n. 12.711, os aportes de recursos destinados às universidades pesquisadas foram incrementados, tendo seu patamar mais elevado em 2016.

A partir de 2017, justamente um ano após totalizar o percentual máximo de reserva, as universidades passaram a experimentar quedas que, em 2020, tiveram reduções expressivas, conforme apresentado na Tabela 5.

Tabela 5. Dotações orçamentárias na rubrica 4002 - Assistência Estudantil entre 2012-2020 (em reais)

\begin{tabular}{cccccccccc}
\hline IES & $\mathbf{2 0 1 2}$ & $\mathbf{2 0 1 3}$ & $\mathbf{2 0 1 4}$ & $\mathbf{2 0 1 5}$ & $\mathbf{2 0 1 6}$ & $\mathbf{2 0 1 7}$ & $\mathbf{2 0 1 8}$ & $\mathbf{2 0 1 9}$ & $\mathbf{2 0 2 0}$ \\
\hline UFMG & 17.633 .691 & 23.476 .309 & 35.863 .907 & 38.046 .040 & 41.500 .867 & 40.553 .129 & 33.223 .864 & 36.624 .532 & 21.703 .867 \\
\hline UFOP & 6.827 .213 & 7.256 .785 & 8.013 .265 & 9.070 .508 & 9.999 .794 & 9.737 .354 & 9.905 .461 & 10.921 .469 & 6.465 .507 \\
\hline UFU & 12.020 .738 & 13.056 .040 & 15.293 .010 & 20.369 .921 & 22.451 .138 & 21.908 .820 & 20.077 .413 & 21.699 .196 & 12.968 .322 \\
\hline
\end{tabular}

Fonte: Lei Orçamentária Anual, 2020.

Contraditoriamente, com o acesso de estudantes ingressantes pelas PAA, entre os quais encontram-se pessoas de baixa renda que necessitam das Políticas de Assistência Estudantil, as IES viram o aporte de recursos para o PNAES cair. Os valores alocados em 2020, em comparação com 2013, primeiro ano de 
vigência da Lei n. 12.711, sofreram quedas significativas. A situação mais crítica foi verificada na UFOP, que perdeu 10,9\% do valor recebido em 2013. A UFMG perdeu 7,5\% e a UFU, $0,7 \%$.

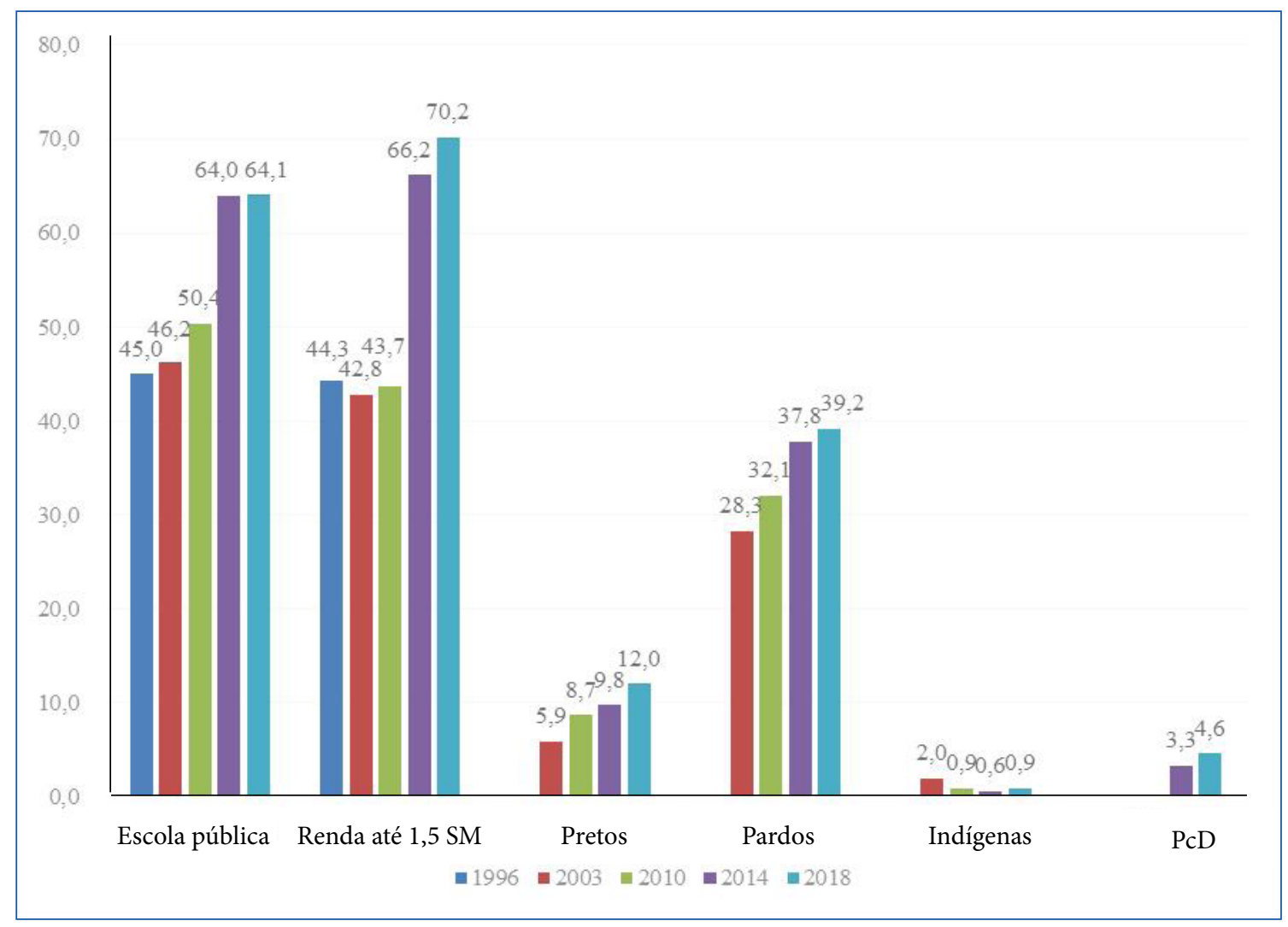

Fonte: Elaboração própria.

Figura 2. Perfil de renda e étnico-racial de ingressantes cotistas

Cotejando com os resultados da V Pesquisa Nacional do Perfil Socioeconômico e Cultural dos(as) Graduandos(as) das IFES (ANDIFES, 2019), Jesus e Meireles (2021) demonstram que a evolução da presença dos grupos beneficiados pelas cotas raciais, público-alvo do PNAES, representava 44,3\%, em 1996, e, em 2018, totalizava $70,2 \%$ do corpo discente universitário.

Esses dados dimensionam o alcance que as Políticas de Assistência Estudantil devem ter, considerando-se a diversidade e as características socioeconômicas desse público. No tocante ao critério de renda, permite-se inferir que, se, em 2010, menos da metade dos estudantes era público do PNAES, em 2018, esse número cresceu em mais de $25 \%$.

O corte de 18,2\% no orçamento de 2021 das universidades e institutos federais realizado pelo Ministério da Educação ${ }^{12}$ atinge, portanto, diretamente as atividades de pesquisa, ensino, extensão e assistência estudantil e incide, de modo mais contundente, nos(as) estudantes, sobretudo ingressantes pelas cotas raciais. A austeridade orçamentária proposta pelo atual governo, de extrema direita ultraconservadora e neoliberal, compromete sobremaneira a sustentabilidade do processo de implementação das PAA, e, por conseguinte, os seus objetivos democráticos de inclusão sociorracial ${ }^{13}$ (GODOI; SANTOS, 2021; GUARNIERI; MELOSILVA, 2017; SILVA, 2020).

Nesse sentido, buscamos analisar quais são os programas de assistência estudantil e congêneres que as instituições investigadas adotam e se desenvolvem algum tipo de programa voltado para trabalhar especificamente com esse público. 


\section{Programas de Assistência Estudantil nas Universidades Pesquisadas}

A PRAE é responsável por administrar as políticas de assistência voltadas para a permanência estudantil na UFMG. Ela está organizada em três eixos de atuação política: ações afirmativas, assistência estudantil e apoio a projetos de estudantes. Segundo a Pró-reitora Adjunta, são realizados os seguintes programas: Programa Meu Lugar (auxílios financeiros para manutenção, transporte, moradia, material acadêmico, aquisição de óculos, estudantes com filhos, inclusão digital), Programa Alimentação, Moradia Universitária, Transporte Universitário, Assistência à Saúde.

Quanto à existência de políticas de permanência específica para o público estudantil ingressante pelas cotas raciais, a Pró-reitora identificou quatro programas, quais sejam: 1) Programa de Apoio às Ações Afirmativas; 2) Projeto Redigir; 3) Projeto Giz; e 4) Programa Seu Lugar.

O Programa de Apoio às Ações Afirmativas consiste em subsidiar, por meio de recursos financeiros, propostas relacionadas às atividades concebidas e executadas pelos próprios estudantes de graduação e pósgraduação, organizados em coletivos, grupos de estudos e pesquisas, observatórios, projetos, programas e similares, que tematizem ações afirmativas no âmbito da instituição. A submissão da candidatura das propostas é feita por meio de edital público.

Já o Projeto Redigir: Oficina de Leitura e Produção de Textos visa contribuir com o desenvolvimento de habilidades de escrita e de leitura de gêneros textuais acadêmicos, como artigos científicos, esquema, resumo, resenha, projeto e relatório de pesquisa, bem como discutir e refletir vários aspectos linguísticos relacionados à escrita de artigos científicos.

O Projeto Giz: Percursos Formativos Discentes consiste em ofertar oficinas, com o intuito de potencializar as habilidades acadêmicas dos estudantes por meio do uso de ferramentas tecnológicas. Essa ação é desenvolvida em parceria com a Diretoria de Inovação e Metodologia de Ensino.

Por fim, o Programa Seu Lugar diz respeito à concessão de bolsas de auxílio para as seguintes situações: 1) estudantes em situação de vulnerabilidade com o risco de evasão ou de abandono da instituição; e 2) bolsas emergenciais para estudantes em risco pessoal ou social. A liberação dessas bolsas passa por uma criteriosa análise socioeconômica e pelo acompanhamento técnico realizado pela equipe da PRAE.

De acordo ainda com a Pró-reitora Adjunta, todos os recursos financeiros para custear essas políticas de permanência estudantil são oriundos do PNAES. Contudo, em virtude dos cortes orçamentários verificados nos últimos anos, a UFMG precisa complementar o financiamento desses programas com recursos próprios.

Na UFOP, o órgão responsável pela assistência estudantil tem status de Pró-reitoria e é responsável por "proporcionar as condições de acesso e permanência aos estudantes, técnicos administrativos e docentes da instituição, garantindo assim o bem-estar psicossocial de toda a comunidade [universitária]" (UFOP, 2019). A Pró-reitoria conta com três coordenadorias: 1) de Assistência Estudantil; 2) de Restaurantes Universitários; e 3) de Saúde.

Em consonância com o Fórum Nacional de Pró-reitores de Assuntos Comunitários e Estudantis (FONAPRACE), o Plano de Desenvolvimento Institucional (PDI) fixou dois objetivos estratégicos: 1) fortalecer as Políticas de Assistência Estudantil na UFOP; e 2) terceirizar serviços de manutenção dos equipamentos dos restaurantes universitários.

Uma parte dos recursos oriundos do PNAES é destinada à realização de três programas de bolsas: 1) Assistência Prioritária (bolsa alimentação; bolsa permanência; e auxílio moradia; 2) Apoio e Acompanhamento (BIDA - Incentivo Acadêmico), e 3) Inclusão e Cidadania (PIDIC - Incentivo à Diversidade e à Convivência). Esses últimos foram criados recentemente e buscam assimilar demandas decorrentes da nova reconfiguração que a universidade atravessou a partir da chegada dos(as) estudantes ingressantes das PAA. 
A Pró-reitoria de Assuntos Estudantis da UFU é a mais nova entre as demais IES, sendo criada no ano de 2016. Ela atua nas dez áreas do Programa Nacional de Assistência Estudantil (PNAES), por meio de benefícios, diretos e indiretos, nas áreas de esporte e lazer, moradia, alimentação, acessibilidade, transporte, atenção à saúde, inclusão digital, cultura, creche, apoio pedagógico, combate às discriminações de gênero, de diversidade sexual e étnico-raciais aos(às) estudantes de graduação.

Além das áreas de atuação no ensino técnico e na pós-graduação, essa Pró-reitoria desenvolve também o Programa Milton Santos aos(às) estudantes estrangeiros(as) (Promisaes); ${ }^{14}$ o Programa de Bolsas de Permanência, aos(às) estudantes indígenas e quilombolas; e o Programa de Acessibilidade na Educação Superior (INCLUIR), aos(às) estudantes PCD (Pessoas com Deficiência).

No que tange às ações específicas que foram motivadas pela Lei n. 12.711, há um entendimento, por parte da PROAE da UFU, de que todos os seus programas atendem a estudantes ingressantes pelas PAA. Entretanto, essa é uma das lutas da Diretoria de Estudos e Pesquisas Afrorraciais (DIEPAFRO) e do NEAB que ainda não foram atendidas. Ela consiste na defesa pelo recorte étnico-racial nesses programas, ou seja, não há a criação específica, até o momento, de programas voltados para os(as) cotistas negros e negras.

Os recursos financeiros das ações realizadas pela PROAE têm como origem: 1) PNAES para estudantes da graduação; 2) ação orçamentária - 2994 para estudantes do ensino técnico; 3) auxílios de acessibilidade para os quais poderão ser utilizados recursos do Programa de Acessibilidade na Educação Superior (INCLUIR); 4) o Programa Milton Santos; 5) o Programa de Bolsas de Permanência (PBP); e 6) recursos próprios destinados à manutenção da universidade, oriundos do Tesouro Nacional. Além disso, há necessidade de complemento por parte da UFU.

A análise conjunta das três instituições investigadas aponta que as PAA influenciam, de forma direta ou indireta, as Pró-reitorias de Assistência Estudantil a desenvolverem programas voltados para os(as) estudantes ingressantes pelas cotas raciais. Essa influência tem sido ocasionada por pressões exercidas pelo movimento negro, pela atuação dos Núcleos de Estudos Afro-brasileiros e Indígenas e, sobretudo, por meio das lutas realizadas por coletivos estudantis negros organizados. Ao ingressarem no espaço acadêmico, esses sujeitos vão contribuindo para o processo de implementação dessas políticas, bem como para a construção de outra universidade no século XXI. Uma universidade plural, diversa e, quem sabe um dia, antirracista.

Nesse sentido, do ponto de vista simbólico, as PAA têm ocasionado, de fato, uma verdadeira democratização, haja vista a inserção de novos sujeitos, negros e negras, hoje presentes no ambiente universitário. Contudo, para efetivação da permanência e do sucesso acadêmico dessas pessoas, torna-se cada vez mais necessário garantir os recursos orçamentários oriundos do PNAES. Ainda que cientes de que políticas de permanência não se restringem às condições materiais para a continuidade das PAA, nos próximos anos, é imprescindível haver mobilização social, visando assegurar os recursos financeiros direcionados à política estudantil e destinados à IES.

\section{Considerações Finais}

A intenção deste estudo foi investigar as condições materiais e simbólicas oferecidas por três universidades federais mineiras, que contribuem para a permanência de graduandos(as) negros(as) ingressantes por meio das PAA. Os resultados alcançados apontam que essas políticas constituem, neste século XXI, importante marco histórico a favor da democratização do acesso ao Ensino Superior. Essas políticas contribuem, ainda, para promover equidade socioeconômica, étnico-racial e de gênero. Logo, os cursos ofertados pelas IES contam hoje com maior representatividade de gênero, cor/raça e classe social. 
A ampliação do ingresso de estudantes negros e negras de baixa renda se dá, entretanto, em um cenário sociopolítico de gestão autoritária, negacionista e neoliberal, a qual promove, ao longo dos anos, sistematicamente, cortes bastante drásticos nos recursos destinados ao PNAES. Cabe ressaltar que esse plano é hoje a principal fonte financeira de manutenção das Políticas de Assistência Estudantil desenvolvidas nas instituições.

A pesquisa revela, portanto, que, para a continuidade das PAA nos próximos anos, torna-se imprescindível discutir, de maneira séria e responsável, acerca de uma Política de Assistência Estudantil que leve em conta as especificidades socioeconômicas, étnico-raciais e de gênero, entre outras, referentes ao novo sujeito, negro e negra, ingressante no Ensino Superior público por meio dessas políticas. Para tal, será preciso inclusive pensar acerca de uma rubrica específica orçamentária capaz de contemplar a permanência material e simbólica desse público.

O estudo elucidou que duas das instituições investigadas desenvolvem programas direcionados, sobretudo, à formação de estudantes ingressantes pelas cotas raciais. Já na UFU, a institucionalização de ações voltadas para esse público tem sido tensionada pela DIEPAFRO e pelo NEAB. Nessa perspectiva, é relevante notar o protagonismo do movimento negro, dos Núcleos de Estudos Afro-brasileiros e Indígenas e dos coletivos estudantis negros em relação ao processo de implementação das PAA.

Por fim, o processo de democratização do Ensino Superior está intrinsecamente relacionado, não só ao acesso, mas também, conforme discutido, à garantia das condições materiais e simbólicas capazes de assegurar a permanência do público estudantil ingressante pelas PAA. Logo, compreender melhor as normas, os programas e os orçamentos financeiros destinados às Políticas de Assistência Estudantil das IES, de fato, é fundamental.

\section{Contribuição dos Autores}

Problematização e Conceitualização: Silva NN; Santos AP; Reis JMS; Metodologia: Silva NN; Santos AP; Reis JMS; Análise: Silva NN; Santos AP; Reis JMS; Redação: Silva NN; Santos AP; Reis JMS.

\section{Notas}

1. Segundo a pesquisadora Maria Salete Magnoni (2016), a luta pelo acesso e a permanência nas universidades brasileiras já é de longa data. Ela considera que, nas primeiras décadas da República brasileira, Lima Barreto (18811922) denunciava o caráter elitista da educação superior, vista na época como trampolim para a obtenção de cargos públicos ou casamentos vantajosos (MAGNONI, 2016).

2. Inicialmente, a proposta da pesquisa era focar nas onze universidades federais mineiras. Todavia, neste momento, será apresentado o resultado dessas três instituições, que representam uma amostra de um terço do total.

3. Raça é aqui entendida como uma construção científica, sociocultural e política. Para Guimarães, a sociologia deve compreendê-la como "discursos sobre as origens de um grupo, que usam termos que remetem à transmissão de traços fisionômicos, qualidades morais, intelectuais, psicológicas etc., pelo sangue” (2003, p. 96), os quais geralmente dizem respeito às identidades sociais coletivas.

4. Nos termos do Estatuto da Igualdade Racial (Lei n. 12.288/2010), entende-se a categoria negro(a) como a população que se autodeclara preta ou parda, de acordo com a classificação adotada pelo Instituto Brasileiro de Geografia e Estatísticas (IBGE). 
5. A Rede foi criada por meio da Lei n. 11.892, de 29 de dezembro de 2008, pelo então presidente da república Luiz Inácio Lula da Silva, e é composta pelos Institutos Federais de Educação, Ciência e Tecnologia, pela Universidade Tecnológica Federal do Paraná, pelos Centros Federais de Educação Tecnológica (CEFET-RJ e CEFET-MG), pelas Escolas Técnicas vinculadas às universidades federais e pelo Colégio Pedro II.

6. O professor Sílvio de Almeida o entende como "uma decorrência da própria estrutura social, ou seja, do modo 'normal' com que se constituem as relações políticas, econômicas, jurídicas e até familiares, não sendo uma patologia social e nem um desarranjo institucional. Aqui, considera-se que comportamentos individuais e processos institucionais são derivados de uma sociedade cujo racismo é regra e não exceção. Nesse caso, além de medidas que coíbam o racismo individual e institucionalmente, torna-se imperativo pensar sobre mudanças profundas nas relações sociais, políticas e econômicas. Pela complexidade das ligações que apresenta com a política, a economia e o direito, é importante falar mais sobre o racismo estrutural" (ALMEIDA, 2019, p. 38).

7. O partido político Democratas (DEM), em 2009, apresentou uma ação contra a Universidade de Brasília, questionando a reserva de $20 \%$ das vagas previstas no vestibular para preenchimento a partir de critérios étnico-raciais. O STF julgou a Arguição de Descumprimento de Preceito Fundamental (ADPF) n. 186/2012, posicionando-se favorável à constitucionalidade das Ações Afirmativas no país.

8. Cabe ressaltar a atuação sociopolítica e educativa desempenhada pelo Programa Ações Afirmativas na UFMG, desde 2002, idealizado pela professora emérita e titular Nilma Lino Gomes e sediado na Faculdade de Educação, e sua importante contribuição no processo de implementação das PAA tanto na graduação quanto na pós-graduação da instituição.

9. Concede o adicional de $10 \%$ na pontuação obtida no vestibular a candidatos(as) que frequentaram escola pública da $5^{a}$ série do Ensino Fundamental ao último ano do Ensino Médio e acréscimo de 5\% ao bônus se ele(a) se autodeclarasse negro(a). O grupo estudantil com esse perfil poderia ter sua pontuação aumentada em $15 \%$.

10. A instituição já contava com a Fundação Universitária Mendes Pimentel (Fump) sem fins lucrativos, que era responsável por prestar assistência estudantil aos discentes em condição socioeconômica vulnerável. Com a criação da PRAE, coube à Fundação executar a política de assistência estudantil.

11. Instituído pelo Decreto n. 7.234, de 19 de julho de 2010 (BRASIL, 2010a)

12. O Sindicato Nacional dos docentes das Instituições do Ensino Superior (ANDES) publicou uma nota técnica argumentando que o orçamento previsto para 2021 sufoca as IES, visto que, "de 2015 para cá, com valores corrigidos pela inflação, as despesas correntes do MEC caíram de R\$ 63,7 bilhões para R \$ 45,9 bilhões previstos para 2021. A queda dos investimentos foi vertiginosa, saindo de R \$ 19,1 bilhões em 2015 para R \$ 3 bilhões previstos para 2021. Em 2020, a execução de despesas correntes foi de apenas R $\$ 41,3$ bilhões e de investimentos foram apenas R \$ 3,4 bilhões”. Disponível em: https://www.andes.org.br/conteudos/nota/ nOTA-dA-dIRETORIA-nACIONAL-dO-aNDES-sN-oRCAMENTO-dE-2021-sUFOCA-aINDA-mAIS-aSuNIVERSIDADESO. Acesso em: 13 jul. 2021.

13. Em plena situação de calamidade de saúde pública mundial ocasionada pela Covid-19, que neste momento já causou mais de 600 mil mortes (subnotificadas) no Brasil, o teto de gastos, por meio da Emenda Constitucional n. 95, aprovada em 2016 por Michel Temer, que congela os investimentos sociais e gastos públicos (com saúde e educação, principalmente) por 20 anos, continua ainda hoje vigente.

14. O Projeto Milton Santos de Acesso ao Ensino Superior (Promisaes) é desenvolvido por meio de subsídio financeiro do MEC, e tem o objetivo de conceder auxílio financeiro por meio de bolsa a estudantes estrangeiros, em especial, os africanos, regularmente matriculados em cursos de graduação. 


\section{Referências}

ALMEIDA, S. L. Racismo estrutural. São Paulo: Sueli Carneiro/Pólen, 2019.

ANDIFES [ASSOCIAÇÃO NACIONAL DOS DIRIGENTES DAS INSTITUIÇÕES FEDERAIS DE ENSINO SUPERIOR]. V Pesquisa nacional do perfil socioeconômico e cultural dos (as) graduandos(as) das universidades federais. Brasília, DF: 2019. Disponível em: http://www.andifes.org.br/v-pesquisanacional-de-perfil-socioeconomico-e-cultural-dos-as-graduandos-as-das-ifes-2018/. Acesso em: 27 abr. 2019.

ANDRÉ, M.; LÜDKE, M. Métodos de coleta de dados: observação, entrevista e análise documental. In: ANDRÉ, M.; LUDKE, M. Pesquisa e educação: abordagens qualitativas. São Paulo: E.P.U, 1986. p. 25-45.

ARTES, A.; MENA-CHALCO, J. Expansão da temática das relações raciais no banco de dados de teses e dissertações da Capes. Educação e Pesquisa, São Paulo, v. 43, n. 4, p. 1.221-1.238, 2017. https://doi. org/10.1590/S1517-9702201702152528

BARDIN, L. Análise de conteúdo. Tradução L. Rego. Lisboa: Edições 70, 2006.

BARRETO, P. et al. A produção das ciências sociais sobre as relações raciais no Brasil entre 2012 e 2019. BIB, São Paulo, n. 94, p. 1-35, ago. 2020. https://doi.org/10.17666/bib9405/2021

BRASIL. Decreto n. 7.234, de 19 de julho de 2010. Dispõe sobre o Programa Nacional de Assistência Estudantil - PNAES. Brasília, DF: Presidência da República, 2010a. Disponível em: http://www.planalto. gov.br/ccivil_03/_ato2007-2010/2010/decreto/d7234.htm. Acesso em: 20 jul. 2021.

BRASIL. Lei n. 12. 288, de 20 de julho de 2010. Institui o Estatuto da Igualdade Racial; altera as Leis nos 7.716, de 5 de janeiro de 1989, 9.029, de 13 de abril de 1995, 7.347, de 24 de julho de 1985, e 10.778, de 24 de novembro de 2003.. Brasília, DF: Presidência da República, 2010b. Disponível em: http://www. planalto.gov.br/ccivil_03/_ato2007-2010/2010/lei/112288.htm. Acesso em: 20 fev. 2015.

BRASIL. Lei n. 12.711, de 29 de agosto de 2012. Dispõe sobre o ingresso nas universidades federais e nas instituições federais de ensino técnico de nível médio e dá outras providências. Brasília, DF: Presidência da República, 2012. Disponível em: http://www.planalto.gov.br/ccivil_03/_ato2011-2014/2012/Lei/ L12711.htm. Acesso em: 20 mar. 2013.

BRASIL. Lei n. 13.005, de 24 de junho de 2014. Aprova o Plano Nacional de Educação - PNE e dá outras providências. Brasília, DF: Presidência da República, 2014.

BRASIL. Orçamento da União, Exercício financeiro de 2020. Brasília, DF: Congresso Nacional. Disponível em: https://www.gov.br/economia/pt-br/assuntos/planejamento-e-orcamento/orcamento/ orcamentos-anuais/2021/ploa/Volume\%20I\%20PLOA\%202021.pdf. Acesso em: 10 mar. 2021.

BRASIL. Supremo Tribunal Federal (Plenário). Arguição de Descumprimento de Preceito Fundamental 186/DF. Arguição de descumprimento de preceito fundamental. Atos que instituíram sistema de reserva de vagas com base em critério étnico-racial (cotas) no processo de seleção para ingresso em instituição pública de Ensino Superior. Relator Min. Ricardo Lewandowski, 28 ago. 2021. Disponível em: <http:// portal.stf.jus.br/processos/downloadPeca.asp?id=269432069\&ext=.pdf>. Acesso em: 19 nov. 2020. 
CARVALHO, J. J. A política de cotas no Ensino Superior: ensaio descritivo e analítico do Mapa das Ações Afirmativas no Brasil. Brasília: INCT, 2016. Disponível em: http://www.mpsp.mp.br/portal/page/portal/ documentacao_e_divulgacao/doc_biblioteca/bibli_servicos_produtos/bibli_boletim/bibli_bol_2017/ Bol10_03.pdf. Acesso em: 20 mar. 2018.

DAFLON, V.; FÉRES JUNIOR, J.; CAMPOS, L. Ações afirmativas raciais no Ensino Superior público brasileiro: um panorama analítico. Cadernos de Pesquisa, São Paulo, v. 43, n. 148, p. 302-327, abr. 2013. https://doi.org/10.1590/S0100-15742013000100015.

FERREIRA, N. As pesquisas denominadas “estado da arte”. Educação \& Sociedade, Campinas, v. 23, n. 79, p. 257-272, ago. 2002. Disponível em: http://www.scielo.br/scielo.php?script=sci_arttext\&pid=S0101$73302002000300013 \& \operatorname{lng}=$ en\&nrm=iso. Acesso em: 23 mar. 2007.

FLICK, U. Uma introdução à pesquisa qualitativa. Tradução Sandra Netz. 2. ed. Porto Alegre: Bookman, 2004.

FREITAS, M.; CORNÉLIO, B. “Nós estamos aqui!”: uma análise das reações negras, indígenas e populares aos cortes orçamentários nas universidades públicas através de cartazes de protesto. Confluenze. Rivista Di Studi Iberoamericani, Bologna, v. XIII, n. 1, p. 170-194, 2021. Disponível em: https://confluenze.unibo. it/article/view/13091. Acesso em: 20 jul. 2021.

GODOI, M.; SANTOS, M. Dez anos da lei federal das cotas universitárias: avaliação de seus efeitos e propostas para sua renovação e aperfeiçoamento. Revista de Informação Legislativa. Brasília, DF, n. 229, p. 11-35, jan./mar. 2021. Disponível em: https://www12.senado.leg.br/ril/edicoes/58/229/ril_v58_n229_ p11. Acesso em: 20 jul. 2021.

GOMES, J. B. Ação afirmativa \& princípio constitucional da igualdade. Rio de Janeiro: Renovar, 2001.

GOMES, N. L. O movimento negro no Brasil: ausências, emergências e a produção dos saberes. Política \& Sociedade, Florianópolis, v. 10, n. 18, p. 133-154, abr. 2011. Disponível em: https://periodicos.ufsc.br/ index.php/politica/article/view/2175-7984.2011v10n18p133. Acesso em: 20 mar. 2012.

GOMES, A; MORAES, K. Educação superior no Brasil contemporâneo: transição para um sistema de massa. Educação \& Sociedade, Campinas, v. 33, n. 118, jan./mar. 2012, p. 171-190. https://doi.org/10.1590/ S0101-73302012000100011

GONZAGA, Y. M. Gestão universitária, diversidade étnico-racial e políticas afirmativas: o caso da UFMG. 2017. 225 f. Tese (Doutorado em Educação) - Faculdade de Educação, Universidade Federal de Minas Gerais, Belo Horizonte, 2017. Disponível em: http://hdl.handle.net/1843/BUOS-AQQMYK. Acesso em: 10 fev. 2018.

GOUVEIA, A. J. Democratização do Ensino Superior. Revista Brasileira de Estudos Pedagógicos, Brasília, DF, v. 50, n. 112, p. 232-244, out./dez. 1968.

GUARNIERI, F.; MELO-SILVA, L. Cotas universitárias no Brasil: análise de uma década de produção científica. Psicologia Escolar e Educacional, São Paulo, v. 21, n. 2, p. 183-193, maio/ago. 2017. https:// doi.org/10.1590/2175-3539201702121100

GUIMARÃES, A. S. Como trabalhar com "raça” em sociologia. Educação e Pesquisa, São Paulo, v. 29, n. 1, p. 93-107, jan./jun. 2003. https://doi.org/10.1590/S1517-97022003000100008 
INEP [INSTITUTO NACIONAL DE ESTUDOS E PESQUISAS EDUCACIONAIS ANÍSIO TEIXEIRA]. Relatório ENADE instituição. Brasília, DF: Inep, 2019. Disponível em: http://inep.gov.br/relatorios. Acesso em: 10 mar. 2021.

INEP [INSTITUTO NACIONAL DE ESTUDOS E PESQUISAS EDUCACIONAIS ANÍSIO TEIXEIRA]. Sinopse Estatística do Ensino Superior. Brasília, DF: Inep, [s. d.]. Disponível em: <http://inep.gov.br/sinopsesestatisticas-da-educacao-superior>. Acesso em: 10 mar. 2021.

INEP [INSTITUTO NACIONAL DE ESTUDOS E PESQUISAS EDUCACIONAIS ANÍSIO TEIXEIRA]. Censo da educação superior 2018: divulgação dos resultados. Brasília, DF: Inep, 2019. Disponível em: $<$ http://download.inep.gov.br/educacao_superior/censo_superior/documentos/2019/apresentacao_censo_ superior2018.pdf>. Acesso em: 19 nov. 2020.

JESUS, R.; MEIRELES, E. Caderno Temático IV: políticas afirmativas no Ensino Superior. Brasília, DF: Fonaprace/ANDIFES, 2021. Disponível em: https://cms.ufmt.br/files/galleries/11/471b1598703dc069d61cc5 25602e3ad4a96898f93.pdf. Acesso em: 20 jul. 2021.

MAGNONI, M. S. Lei de Cotas e a mídia brasileira: o que diria Lima Barreto? Estudos Avançados, São Paulo, v. 30, n. 87, p. 299-312, 2016. https://doi.org/10.1590/S0103-40142016.30870017

MOEHLECKE, S. Ação afirmativa: história e debates no Brasil. Cadernos de Pesquisa, São Paulo, n. 117, p. 197-217, nov. 2002. https://doi.org/10.1590/S0100-15742002000300011

PAIXÃO, M. (org.). Relatório anual das desigualdades raciais no Brasil: 2009-2010. Rio de Janeiro: UERJ, 2010. Disponível em: http://www.redesaude.org.br/portal/comunica/201112/includes_publicacoes/01_ Relatorio_20092010_desigualdades\%20raciais.pdf. Acesso em: 15 fev. 2011.

PEIXOTO, M.; ARANHA, A. (orgs.). Universidade pública e inclusão social: experiências e imaginação. Belo Horizonte: Editora UFMG, 2008.

SANTOS, A. P. Gestão universitária e a Lei de Cotas. Curitiba: Appris, 2020.

SANTOS, D. R. B. Para além das cotas. A permanência de estudantes negros no Ensino Superior como Política de Ação Afirmativa. 2009. 214 f. Tese (Doutorado em Educação) - Faculdade de Educação, Universidade Federal de Bahia. Salvador, 2009. Disponível em: https://repositorio.ufba.br/ri/handle/ri/11778. Acesso em: 27 abr. 2019.

SILVA, N. N. As políticas de Ações Afirmativas no Ensino Superior são um problema? In: ROVAI, M. G. (org.). Revisionismos: a universidade esclarece. São Paulo: Mentes Abertas, 2020. p. 153-173.

SILVÉRIO, V. Novas experiências de inclusão: ação afirmativa para negros e nativos no Brasil. Revista Sinais Sociais, Rio de Janeiro, v. 12, p. 155-185, 2018. Disponível em: https://portaldev.sesc.com.br/wps/wcm/ connect/2399f00f-0ba0-4bae-b225-bee0622532c1/SS34_web.pdf?MOD=AJPERES\&CACHEID=2399f00f0ba0-4bae-b225-bee0622532c1. Acesso em: 25 fev. 2020.

TROW, M. Problems in the transition from elite to mass higher education. Berkeley: Carnegie Comission on Higher Education, 1973.

UNIVERSIDADE FEDERAL DE MINAS GERAIS. Relatório de Gestão do exercício 2019. Belo Horizonte: UFMG, 2020. Disponível em: https://www.ufmg.br/proplan/wp-content/uploads/Relatorio_Gestao_2020.pdf. Acesso em: 20 mar. 2021. 
UNIVERSIDADE FEDERAL DE OURO PRETO. Relatório de Gestão do exercício 2019. Ouro Preto: UFOP, 2020. Disponível em: https://ufop.br/relatorios-de-gestao. Acesso em: 15 abr. 2021.

\section{Sobre os Autores}

Natalino Neves da Silva É professor adjunto da Faculdade de Educação (FaE), Departamento de Administração Escolar (DAE), da Universidade Federal de Minas Gerais (UFMG) e no Programa de Pósgraduação (Mestrado Profissional em Educação e Docência) da mesma unidade (PROMESTRE/FaE/UFMG). Mestre e doutor em Educação pela Universidade Federal de Minas Gerais (UFMG). Membro do Núcleo Gestor do Programa Ações Afirmativas na UFMG.

Adilson Pereira dos Santos é Pró-reitor adjunto de Graduação da Universidade Federal de Ouro Preto (UFOP). Mestre em Educação pela Universidade do Estado do Rio de Janeiro (Uerj) e Doutor em Educação pela Universidade Federal de Minas Gerais (UFMG). Membro do Núcleo de Estudos Afro-brasileiros e Indígenas (NEABI-UFOP). Presidente do Conselho Municipal de Promoção da Igualdade Racial de Ouro Preto.

Jane Maria dos Santos Reis é coordenadora da Divisão de Licenciatura, ligada à Diretoria de Ensino da Pró-reitoria de Graduação da Universidade Federal de Uberlândia (UFU). Mestra e doutora em Educação pela Universidade Federal de Uberlândia (UFU). Vice-coordenadora do Núcleo de Estudos Afro-brasileiros (NEAB-UFU). Coordenadora Executiva do Fórum de Defesa das Cotas Raciais junto ao Ministério Público Federal de Uberlândia.

Recebido: 30 jul. 2021 